Results: Students consistently stated that this experiential learning was eye-opening and provided them with more insights than had they just read about it in a textbook. Since this exercise, the School of Nursing was invited to participate in disaster drills within the community, thus providing additional experiential learning opportunities for the students and enhancing communication and collaboration through partnerships.

Conclusions: Partnerships between schools of nursing and healthcare agencies provide excellent avenues to address disaster preparedness and emergency response training for nursing students and agency staff members.

Keywords: community health; disaster; nursing; preparedness; risk assessment

Prebosp Disaster Med

Israeli Trauma Mass-Casualty Nursing Course G. Hyams; ${ }^{1}$ M. Michaelson; ${ }^{1}$ M. Peretz; $;{ }^{1}$ D. Alboar; ${ }^{2}$ V. Veksler, 3 B. Adini; 3 D. Laor, ${ }^{3}$ A. Blumenfeld; ${ }^{4}$ Z. Rapaport ${ }^{5}$

1. Teaching Center for Trauma, Emergency and Mass Casualty Situations, Rambam Health Care Campus, Haifa, Israel

2. Rabin Medical Center Beilinson Campus, Petach Tikva, Israel

3. Emergency Division, Ministry of Health, Tel Aviv, Israel

4. American Physicians Fellowship for Medicine in Israel

5. Cheryl Spencer School of Nursing, Rambam Health Care Campus, Haifa, Israel

Introduction: Israel is one of the few countries that has had almost 60 years to prepare deal with a variety of masscasualty situations (MCSs).

The importance of professional training of the nursing staff became especially meaningful after recent conflicts, including the Second Lebanon War and Gaza conflict. Facing this reality, it became important to expand and promote the knowledge of the nurses who treat the injured patients in the emergency department. Under the grant of The American Physicians Fellowship (APF), the first Trauma and Mass Casualty Nursing Course was developed. Methods: The course was established as a joint effort Emergency Division of the Israeli Ministry of Health, the Israeli Trauma Society, and the Teaching Center for Trauma, Emergency and MCS at the Rambam Health Care Campus. A total of 25 nurses from 16 hospitals participated. The main subjects were treating injured patients during peacetime and during MCSs, and preparedness for MCSs. The course included lectures and simulation drills for expanding the cognitive knowledge and psychomotor skills. Participants in the first course were trained to be the instructors.

Results: The average grade for the lectures and simulations was 4.55 (out of 5), for the knowledge gained, 4.34 (out of 5), and for the organization, 4.77 (out of 5). Participants stressed the importance of the course, as well as the knowledge and practical skills gained.

Conclusions: Professional knowledge is the base for optimal functioning. The Israeli Trauma Mass-Casualty Nursing Course is the first course for training nursing teams and providing knowledge and practical strategies for treating the injured patient during peacetime and MCSs.

Keywords: education; Israel; mass-casualty incident; nurse; training; trauma

Prehosp Disast Med
Methods of Teaching Medical and Non-Medical Personnel to Provide First Aid during Disasters

G.G Rosbchin; V.O. Krylyuk

Ukraine

Introduction: This study examined first aid training.

Methods: Three hundred twenty non-medical students who passed training at the Ukrainian Scientific and Practical Center for first aid and disaster medicine were studied. The teaching lasted for 48 hours. Students were placed into two groups. The first was made up of 120 students who were taught using the standard methods of teaching. The second group, which was made up of 200 students, was taught using algorithms and practical skills and worked with mankins and moulaged volunteers. The second group also trained at a morgue and the emergency department of Kiev City Hospital. Each group was evaluated with tests at the beginning and end of the training. Results: Participants in the first group correctly answered an average of $76 \%$ of the test questions before training, and $84 \%$ after training was complete. The second group averaged $74 \%$ and $95 \%$ respectively. At the end, the speed of implementation of manipulations in the second group was 45 seconds less than the first group. During implementations of practical manipulations of a neck collar and bandages, the first group experienced 48 errors, wile the second group experienced only 12 .

Conclusions: Moulaging methods, emergency department experience, and algorithms for providing medical care are instrumental for the education and training of the theoretical and practical skills.

Keywords: disasters; education and training; first aid; medical personnel; non-medical personnel

Prehosp Disaster Med

Disaster Risk Reduction in the Western Pacific Region: Strengthening Health System Preparedness for Public Health Emergencies through Safer Health Facilities

Arturo Pesigan, MD; Lester Sam Geroy, MD, MPH

World Health Organization, Regional Office for the Western Pacific (WHO/WPRO), Philppines

Background: Countries in Asia and the Pacific are most affected by disasters due to natural hazards. Nine of the top 10 countries with the highest number of disaster-related deaths in 2008 were in Asia. Recent events have shown the occurrence of hydro-meteorological, geophysical, climatological, biological, and human-generated hazards in the region. Apart from economic losses, deaths, and injuries, natural hazards affect the healthcare system through infrastructure damages and functional disruption.

Methods: The World Health Organization Regional Office for the Western Pacific (WHO/WPRO), with support from the European Commission Humanitarian Aid Department (ECHO) launched the Regional Roll-Out of the International Strategy for Disaster Reduction (ISDR) Campaign on Hospitals Safe from Disasters by strengthening health systems preparedness for emergencies through safer hospitals and health facilities. The campaign has five key result areas: (1) assessment of hospital vulnerability; (2) tools and guidelines for disaster management planning, (3) enhance- 
ment of capacity for preparedness and response; (4) provision of technical guide for structural integrity of health facilities; and (5) advocacy and awareness of safe health facilities campaign. Target countries included Cambodia, Lao PDR, Philippines, and Vietnam.

Conclusions: The strategy has provided positive results in terms of advocacy, technical resources on preparedness of hospitals, assessment of health facilities, and capability enhancement of health emergency managers at the national and local levels. Building strong infrastructures with a prepared staff that could remain functional during natural hazards is an integral part of disaster risk reduction. Advocacy, sharing of experiences, partnership with donors and private sectors, participation of civil society, and development of national policies will be enhanced as a next step. Keywords: Asia; disaster; health; preparedness; public health; risk reduction; Western Pacific

Prebosp Disaster Med

\section{Education and Training in Disaster Medicine in Belgium} J.B. Gillet; ${ }^{1}$ A. Meulemans, ${ }^{2}$ C. Lebaupin, ${ }^{2}$ J. Stroobants ${ }^{3}$

1. KU Leuven, Emergency Department, Leuven, Belgium

2. Clinique Saint Pierre, Ottignies, Belgium

3. AZ Middelheim, Antwerpen, Belgium

Introduction: In Belgium, as in many other countries, the courses of disaster medicine vary considerably in terms of objectives, basic requirements, acquired skills, learning methods, and content. The lack of coherence leads to two types of problems:

1. The various trainings do not supply skills and qualifications at the same level; and

2. The authorities cannot use the acquired skills and knowledge as functioning standards.

Methods: Representatives of the seven Belgian universities and representatives of scientific and professional societies in emergency medicine came together to:

1. Make an inventory of the existing training programs; and

2. Define a common vision for the future.

Results: A consensus was agreed upon to determine four levels of education:

1. A basic level for each relief professional in different disciplines. The objective is to allow those professionals to understand the organization of emergency medical services and to collaborate with it: theoretical course of four hours;

2. A basic level for doctors and specialized nurses working in an emergency department. The objective is to train them in case they are faced with a large number of victims, pending the arrival of reinforcements: 20 hours, with a field exercise;

3. A basic level for emergency physicians and nurses for the responsibility function of operational director of emergency medical services including risk assessment: 15 days of courses with a tabletop exercise, a field exercise, and an evaluation; and

4. A higher level for doctors in education, research, and risk analysis: Master after Master: one year.

Conclusions: It was decided unanimously that harmonization of training is necessary in Belgium. A large medical consensus was researched to keep four levels of education and to harmonize the contents and duration of the different trainings.

Keywords: Belgium; disaster medicine; education; training

Prebosp Disaster Med

Bio-Terror Interactive Software and its Impact on the Knowledge of First Responders

Itay Fogel; Liat Tusk-Helerman; Ram Sagi

CBRN Medicine Branch, Medical Corps Headquarters, Israel

Defense Forces, Israel

Preparedness for a bioterrorist attack depends, among other things, on the early identification of the event by a group of sentinels, which by definition, includes physicians, paramedics, and nurses who first encounter affected individuals.

Data indicated that the knowledge and awareness level of medical staff regarding bioterrorist agents is low- a fact that may have a negative impact on the speed with which the agents are identified, and thus, the ability to affect the course of the diseases they cause.

In order to improve the knowledge of medical staff regarding bioterrorism agents, interactive software was developed and into four units, each one dealing with one of the four bioterrorism agents: (1) anthrax; (2) plague; (3) smallpox; and (4) botulinum.

The software was designed for use by medical personnel in hospitals or community clinics, and features a convenient and user-friendly work interface that independently manages clinical cases and provides feedback. Similarly, the software was designed for use in any large institution: )hospitals, military medical schools, etc.), so it can be used at a time that is convenient for the attending physician, in almost any place without the need for a trained instructor.

The results of surveys and tests administered among physicians and paramedics who sampled the software at the military medical school indicate substantial student satisfaction with the new learning method as well as a significant increase in knowledge regarding bioterrorism agents.

Since this learning tool is intended to increase knowledge and awareness among physicians and paramedics, we anticipate that the guide ultimately will improve the preparedness of the medical system for a bioterrorist attack.

Keywords: bioterrorism; computer; first responders; software Prehosp Disaster Med

\section{Managing Surge Capacity-Lessons Learned from a National, Mass-Casualty Simulation Exercise G.P.H. Choa; M.K.F. Leong \\ Singapore General Hospital, Singapore}

Introduction: Surge capacity is a challenge that all emergency departments face during a mass-casualty situation. A full-scale, mass-casualty simulation exercise at Singapore General Hospital and the lessons learned will be presented. The hospital's experience in creating temporary intensive care unit beds and the presence of a forward deployed anesthesist and surgeon at the emergency department also will be presented.

Methods: A real-time simulation exercise with trained volunteers acting as casualties was conducted by the Ministry of Health. The hospital had to submit its mass-casualty 